\title{
The Luminescence of the Scheelite $\mathrm{NaBi}\left(\mathrm{MoO}_{4}\right)_{2}$
}

\author{
ZB. MAZURAK* AND G. BLASSE \\ Physical Laboratory, State University, P.O. Box 80.000, 3508 TA Utrecht, \\ The Netherlands \\ AND J. LIEBERTZ \\ Institut für Kristallographie der Universität zu Köln, Zülpicherstrasse 49, \\ D-5000 Cologne 1, West Germany
}

Received June 20, 1986

\begin{abstract}
The luminescent properties of the scheelite $\mathrm{NaBi}\left(\mathrm{MoO}_{4}\right)_{2}$ are reported. Below $50 \mathrm{~K}$ an efficient, red emission occurs. The results agree with those for other bismuth molybdates. The decay measurements indicate an energy level structure of the emitting state which is very similar to that in $\mathrm{PbMoO}_{4}$. The distribution of the $\mathrm{Na}^{+}$and $\mathrm{Bi}^{3+}$ ions is probably short-range ordered. (c) 1987 Academic Press, Inc.
\end{abstract}

\section{Introduction}

Tungstates and molybdates with scheelite structure are well known for their luminescence $(l, 2)$. Among these $\mathrm{CaWO}_{4}$ and $\mathrm{CaMoO}_{4}$ should be mentioned first, the former having been used as an applied Xray phosphor for a long time. The optical transitions take place in the tungstate and molybdate groups and are of the chargetransfer type (2).

It is also known that ions with $s^{2}$ configuration, like $\mathrm{Pb}^{2+}$ and $\mathrm{Bi}^{3+}$, can influence the luminescent properties of the tungstates and molybdates considerably $(1,2)$. In connection with the scheclite structure, $\mathrm{PbWO}_{4}$ and $\mathrm{PbMoO}_{4}$ should be mentioned (3). These compounds have their optical absorption edge and the maximum of their

\footnotetext{
* On leave of absence from Institute of Low Temperature and Structure Research, Polish Academy of Sciences, P.O. Rox 937, 50950 Wroclaw, Poland.
}

green emission band at longer wavelengths than do the corresponding alkaline earth compounds. Bismuth tungstates and molybdates show emission at cven longer wavelength, viz., in the red spectral region (4). However, these bismuth compounds do not have the scheelite structure.

In this paper we wish to report on the luminescence of single-crystal $\mathrm{NaBi}$ $\left(\mathrm{MoO}_{4}\right)_{2}$, which has the scheelite structure (5); i.e., it is isomorphous with $\mathrm{CaMoO}_{4}$ with a statistical distribution of the $\mathrm{Na}^{+}$and $\mathrm{Bi}^{3+}$ ions on the $\mathrm{Ca}^{2+}$ sites. From an electronic point of view there is a great similarity between $\mathrm{PbMoO}_{4}$ and $\mathrm{NaBi}\left(\mathrm{MoO}_{4}\right)_{2}$, since the $\mathrm{Pb}^{2+}$ and $\mathrm{Bi}^{3+}$ ions are isoelcctronic.

The present study was performed on single crystals. This was also the case for the lead scheelites (3). The bismuth molybdates and tungstates, however, were investigated on powder samples. It will be shown that all data fit together nicely. 


\section{Experimental}

Crystals of $\mathrm{NaBi}\left(\mathrm{MoO}_{4}\right)_{2}$ were grown from the melt (congruent melting temperature ca. $1140 \mathrm{~K}$ ) by the Czochralski method. Stoichiometric mixtures of the chemically pure starting materials $\mathrm{Ni}_{2} \mathrm{CO}_{3}$, $\mathrm{Bi}_{2} \mathrm{O}_{3}$, and $\mathrm{MoO}_{3}$ were prefired at $975 \mathrm{~K}$ for $24 \mathrm{hr}$. In most cases the pulling direction was parallel to the crystallographic $c$-axis, sometimes to the $a$-axis. Suitable pulling rates ranged from 4 to $8 \mathrm{~mm} / \mathrm{hr}$ with a rotation of $15 \mathrm{rpm}$. The crystals obtained have optical quality and exhibited amber color; their lengths reached up to $60 \mathrm{~mm}$, with diameters up to $25 \mathrm{~mm}$ (6). Similar growth conditions and results have been reported by Akimov et al. (7).

One of the crystals was cut and polished to dimensions of $7 \times 7 \times 2.5 \mathrm{~mm}^{3}$.

The optical instrumentation consists of a spectrofluorometer MPF 44B equipped with an Oxford helium flow cryostat. Decay times were measured using a photon counting system (EG and $G$ ). The excitation source is a $\mathrm{N}_{2}$-flash lamp (8). Absorption measurements were performed at room temperature on a Perkin-Elmer Lambda 7 spectrophotometer.

\section{Results}

Below $100 \mathrm{~K}$ the scheelite $\mathrm{NaBi}\left(\mathrm{MoO}_{4}\right)_{2}$ shows a red emission under long-wavelength ultraviolet excitation. Figure 1 shows the emission and excitation spectra of this luminescence at $4.2 \mathrm{~K}$. The emission band shows a maximum at $600 \mathrm{~nm}$, the corresponding excitation maximum is $385 \mathrm{~nm}$. Upon $395 \mathrm{~nm}$ excitation (i.e., near the onset of the excitation spectrum) the emission maximum is slightly shifted to about 610 nm.

Optical absorption spectra on single crystals show an intense absorption for $\lambda<400$ $\mathrm{nm}$. Diffuse reflection spectra on powdered samples show the maximum of the first $a b-$

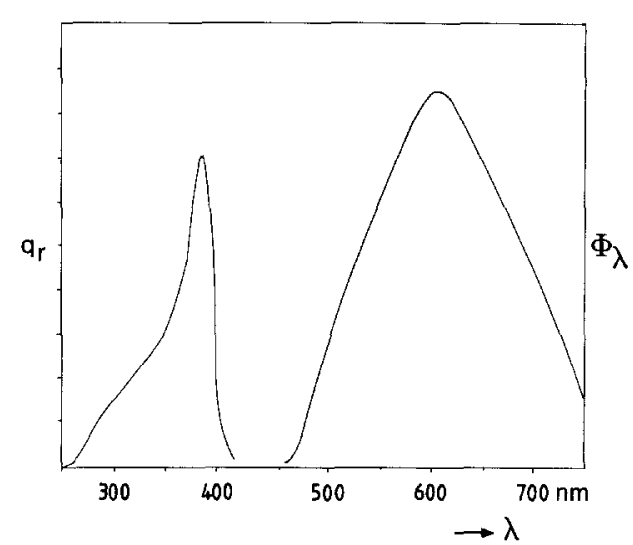

FIG. 1. Emission and excitation spectra at $4.2 \mathrm{~K}$ of the luminescence of a $\mathrm{NaBi}\left(\mathrm{MoO}_{4}\right)_{2}$ single crystal. Emission spectrum recorded for excitation at $385 \mathrm{~nm}$. Excitation spectrum recorded for emission $600 \mathrm{~nm} . q_{\mathrm{r}}$ gives the relative quantum output in arbitrary units. $\Phi_{\lambda}$ gives the spectral radiant power per constant wavelength interval in arbitrary units.

sorption band at about $370 \mathrm{~nm}$ at $300 \mathrm{~K}$. Assuming that the thermal shift of this maximum is similar to that observed for $\mathrm{Pb}$ $\mathrm{MoO}_{4}$ (3), we estimate the position of the first absorption band of $\mathrm{NaBi}\left(\mathrm{MoO}_{4}\right)_{2}$ at 4.2 $\mathrm{K}$ at about $360 \mathrm{~nm}$. This is a strikingly different value from the excitation maximum $(385 \mathrm{~nm})$, so that the latter cannot be considered to correspond to an absorption maximum. This is due to the well-known phenomenon that in strongly absorbing crystals excitation into the absorption maximum is not very effective, because the excitation cannot enter the crystal and considerable radiationless losses occur in the surface layer.

From the emission and absorption maximum we derive a value of $12,000 \mathrm{~cm}^{-1}$ for the Stokes shift of the luminescence.

In Figure 2 the temperature dependence of the luminescence intensity is given. Quenching occurs above $20 \mathrm{~K}$. The intensity has dropped to $50 \%$ at about $40 \mathrm{~K}$. This figure shows also the temperature dependence of the decay time of the luminescence. All decay curves are purely exponential. At the lowest temperatures there is 


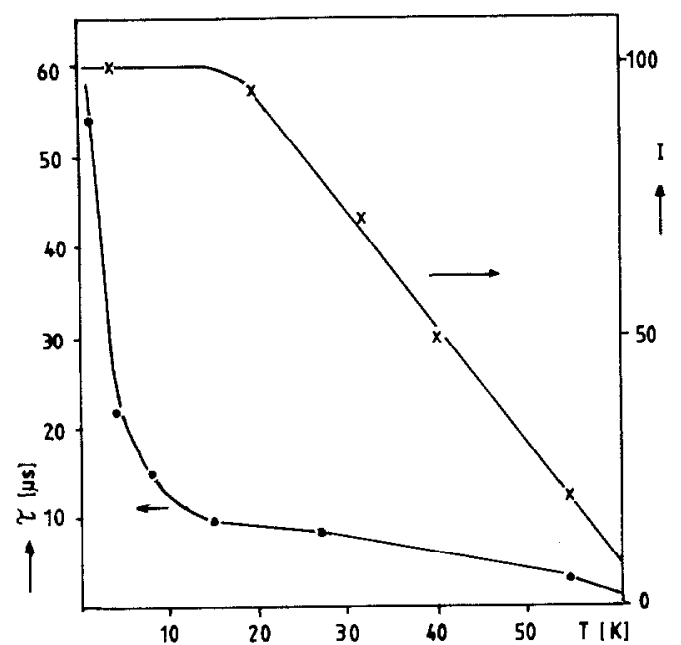

FIG. 2. Decay times of the 600-nm emission of NaBi$\left(\mathrm{MoO}_{4}\right)_{2}$ as a function of temperature (black points). The line indicated by crosses gives the relative emission intensity $(I)$.

a rapid increase of the decay time for decreasing temperature. Even at $1.5 \mathrm{~K}$ no plateau value has been attained. This indicates the presence of a very shallow optical trap. Exactly the same has been observed for $\mathrm{Pb}$ $\mathrm{MoO}_{4}$. The trap depth is of the order of a few wavenumbers. For higher temperatures there is a continuous decrease of the value of the decay time. Since temperature quenching occurs already above $20 \mathrm{~K}$, we did not analyze the temperature dependence of the decay time any further.

\section{Discussion}

In Ref. (4) it was shown that the luminescence of bismuth molybdates is in the red spectral region. The Stokes shift in these compounds amounts to $\sim 11,000 \mathrm{~cm}^{-1}$ for molybdate tetrahedra and $\sim 9,000 \mathrm{~cm}^{-1}$ for molybdate octahedra. The value of 12,000 $\mathrm{cm}^{-1}$ for the red emission of $\mathrm{NaBi}\left(\mathrm{MoO}_{4}\right)_{2}$ fits into the series of results, the scheelitestructure containing tetrahedral molybdate groups. Actually the luminescence properties of $\gamma^{\prime}-\mathrm{Bi}_{2} \mathrm{MoO}_{6}, \mathrm{Bi}_{2} \mathrm{Mo}_{2} \mathrm{O}_{9}$, and $\mathrm{Bi}_{2}$
$\left(\mathrm{MoO}_{4}\right)_{3}$, all with tetrahedral coordination (3), are very similar to those of $\mathrm{NaBi}$ $\left(\mathrm{MoO}_{4}\right)_{2}$.

The precise nature of the optical transitions involved is not clear, but they have a considerable metal-to-metal charge-transfer character, i.e., $\mathrm{Bi}^{3+} \rightarrow \mathrm{Mo}^{6+}$. The optical transitions of the molybdate group and of the $\mathrm{Bi}^{3+}$ ion, when separated from each other, are situated at higher energy than the transitions under discussion (2).

The emission of $\mathrm{NaBi}\left(\mathrm{MoO}_{4}\right)_{2}$ seems to consist of one band only. By exciting into the tail of the absorption it was possible to observe an emission at slightly longer wavclength. This would be a surprising result if the distribution of $\mathrm{Na}^{+}$and $\mathrm{Bi}^{3+}$ ions on the larger cation sublattice of the scheelite structure were completely random. In that case the molybdate groups would have a variable number of $\mathrm{Bi}^{3+}$ ions around them, so that several emission bands are to be expected. Our result suggests that the $\mathrm{Na}^{+}$and $\mathrm{Bi}^{3+}$ ions, which according to X-ray diffraction are not longrange ordered, are short-range ordered. This confirms an early prediction by Van Santen (9). Also, the vibrational spectra of scheelites $M^{+} M^{3+}\left(\mathrm{MoO}_{4}\right)_{2}$ have shown that there must be a considerable amount of short-range order in these compounds $(10)$. The additional emission excited in the absorption tail is then ascribed to a molybdate group with more than the average number of $\mathrm{Bi}^{3+}$ ions around it.

The low quenching temperature of the luminescence of $\mathrm{NaBi}\left(\mathrm{MoO}_{4}\right)_{2}$ has also been observed for the other bismuth molybdates. The configurational coordinate model shows clearly that broadband red emissions are not expected to have high quenching temperatures (11).

There is a striking analogy between the decay times of $\mathrm{PbMoO}_{4}$ (3) and those of $\mathrm{NaBi}\left(\mathrm{MoO}_{4}\right)_{2}$ in the temperature region where temperature quenching is of no importance. This shows that the energy level 
structure of the emitting state in these compounds must be similar. This result is not unexpected in view of the similarity in electronic configuration. The energy level structure is not easy to unravel nor to account for. It has been suggested (2) that the molybdate emission is due to a triplet-singlet transition. This has been confirmed by Van der Waals et al. (12). However, the heavy $s^{2}$ ions form a disturbing factor and will increase the influence of spin-orbit coupling. It cannot be excluded that the level splitting of a few wavenumbers, which follows from the temperature dependence of the decay time, is due to a splitting of the triplet as observed in more simple systems (I2). This warrants further research.

\section{Acknowledgment}

The authors thank Mr. E. W. J. L. Oomen for instructive discussions on the decay time measurements.

\section{References}

l. F. A. KRöger, "Some Aspects of the Luminescence of Solids," Elsevier Amsterdam (1948).

2. G. Blasse, Struct. Bond. 42, 1 (1980).

3. W. van Loo, Phys. Stat. Sol. A 27, 565 (1975); 28, 227 (1975).

4. G. Blasse and L. Boon, Ber. Bunsenges. Phys. Chem. 88, 929 (1984).

5. L. G. Sillén And H. Sundvall, Arkiv. Kemi, Min., Geol. A 17, 1 (1943).

6. H. SCHMIDT, thesis, Köln (1975),

7. S. V. Akimov, T. M. Stolpakova, E. F. DudNIK, AND E. V. SinYakov, Sov. Phys. Solid State 19, 1660 (1977).

8. C. W. M. Timmermans and G. Bi.asse, I. Solid State Chem. 52, 222 (1984).

9. J. H. VAn SAnten, Philips Res. Rep. 5, 282 (1950).

10. W. J. SCHIPPER AND G. Blasse, Z. Naturforschung $B$ 29, 340 (1974).

11. G. RLASSE, in "Radiationless Processes" (B. DiBartolo, Ed.), p. 287, Plenum New York (1980).

12. W. BARENDSWAard, J. VAN TOL, AND J. H. VAN DER WaAls, Chem. Phys. Lett. 121, 361 (1985). 